\title{
Ubiquitin Carboxyl-Terminal Hydrolase 28
}

National Cancer Institute

\section{Source}

National Cancer Institute. Ubiquitin Carboxyl-Terminal Hydrolase 28. NCI Thesaurus.

Code C124091.

Ubiquitin carboxyl-terminal hydrolase 28 (1077 aa, $122 \mathrm{kDa}$ ) is encoded by the human USP28 gene. This protein plays a role in both protein deubiquitination and cellular responses to DNA damage. 